\title{
Usos de la tecnología móvil en los museos de Nueva York
}

\section{Resumen}

Carmen Molina Tamacas

Antropóloga y periodista radicada en Estados Unidos cmolinatamacas@gmail.com

La aplicación de las nuevas tecnologías es todo un reto para las instituciones culturales, y para los museos no es excepción. La tendencia es promover la difusión de la información de acceso, colecciones, conferencias y exposiciones, también para la interacción de forma masiva no solo para los visitantes "reales", sino virtuales.

La mayoría de los museos más representativos de la Gran Manzana cuentan con aplicaciones móviles (apps) que incluyen mapas con geolocalizador, directorios, colecciones, descripciones visuales y audios para hacer la experiencia del usuario tan parecida como a una presencial.

Palabras clave: museos, tecnología, experiencia de usuario, móviles, smartphones, Nueva York, MoMA, Metropolitan Museum of Arts.

\begin{abstract}
The application of new technologies is a challenge for cultural institutions and museums are no exception. The trend is to promote the dissemination of information, collections, conferences, exhibitions and interaction massively, not only for the "real" but virtual visitors.

The most representative museums in the Big Apple have mobile applications (Apps) with GPS, maps, directories, collections, visual and audio descriptions for the user experience in situ and remotely.
\end{abstract}

Key words: museums, technology, user experience, mobile, smartphones, New York, MoMA, Metropolitan Museum of Arts El Observador, de Uruguay el 13 de junio de 2015. Reproducción y edición autorizada. 
"Hola, soy Yoko. Estoy muy feliz de que estés aquí para ver el show. Vamos juntos."

Yoko Ono, la artista conceptual japonesa y viuda de John Lennon, nos toma de la mano para darnos un tour por su más reciente exhibición: "One Woman Show 1960-1970".

Pero ella no está, ni nosotros, en el Museo de Arte Moderno (MoMA). Es una experiencia que podemos vivir gracias a una app que permite navegar por las actuales exposiciones no solo por medio de fotografías, sino por audiotours y descripciones visuales.

Como el MoMA, la mayoría de museos de la Gran Manzana está a la vanguardia respecto a los servicios digitales que prestan tanto a los visitantes, artistas como a los investigadores.

Una app que muestra el mapa del recinto y que nos enseñe las piezas claves es lo de menos, eso ya es obsoleto. Los museos están luchando contra nuestra adicción a las pantallas interactivas. "Nuestra competencia son Netflix y Candy

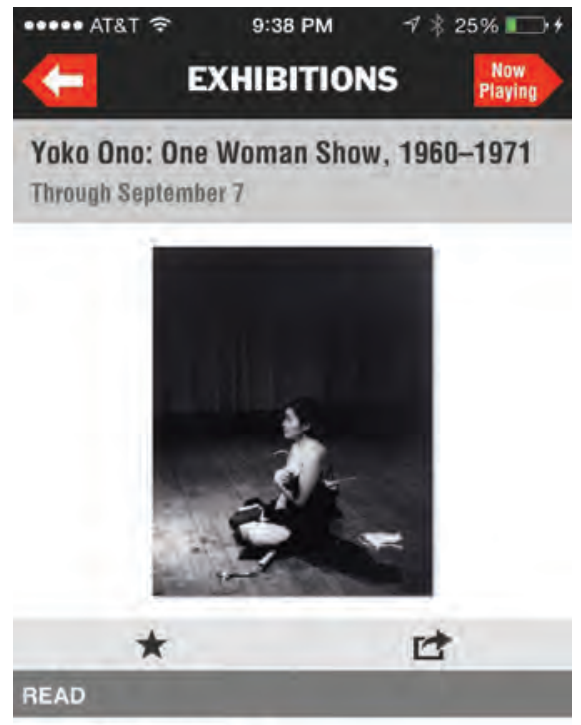

About this exhibition

The Museum of Modern Art presents its first exhibition dedicated exclusively to the work of Yoko Ono, taking as its point of departure the artist's unofficial MoMA debut in late... MORE
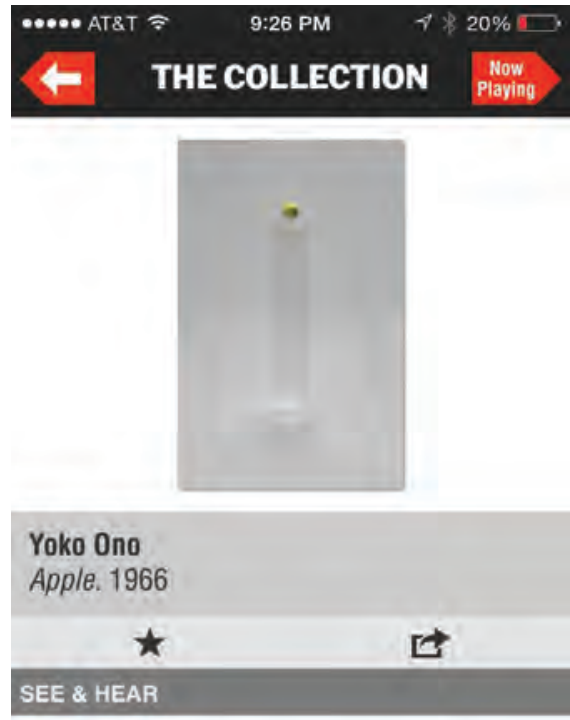

601 | Yoko Ono: One Wo...

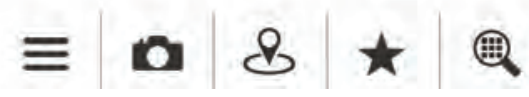


Crush, no otros museos", resumió el jefe de tecnología digital del Museo Metropolitano de Arte (Met), Sree Sreenivasan, en un artículo publicado en Digital Trends. (Enlace http://www.digitaltrends.com/cool-tech/how-museumsare-using-technology/\#ixzz3ccNLqgPB.)

El Met como se le conoce a uno de los museos con las colecciones de arte clásico más importante del mundo está explorando formas para facilitar la experiencia interactiva, añade el reporte. El wi-fi del edificio permite a los visitantes acceder a la app móvil para más información y guías de audio, al tiempo que pueden subir sus fotos a Instagram. Además, está experimentando con tecnologías emergentes, como iBeacon, e incluso con realidad aumentada.

A continuación presentamos una muestra de lo que se puede conocer, aun sin viajar: grandes tesoros culturales, científicos y artísticos al alcance de sus dedos.

\section{Las aguas profundas del MoMA}

"One Woman Show" es una recopilación del trabajo temprano de Yoko Ono, curada por Christophe Cherix. Una de las primeras obras es "Apple", de 1966, la cual fue exhibida en London Gallery y fue la razón de su primer encuentro con Lennon (link con la app).

Esa es una de las exhibiciones actuales del MoMA, pero la app tiene mucho más: también tiene una opción para fotografías; una ruta corta para aquellos que solo dispongan de una hora para visitar el museo, así como un directorio por cada uno de los seis pisos, con las obras más destacadas. El motor de búsqueda ayuda a localizar la leyenda de una obra por medio de su número de audio o palabra clave.

Otros productos interactivos del MoMA son Exhibiciones especiales, MoMA Talks: Conversaciones (audio), Descripciones visuales, Kids y blogs.

Para iPad están disponibles por pago muchas colecciones de eBooks; "Highlights" (\$9.99) incluye 350 obras de las más significativas del arte moderno y contemporáneo, en 380 páginas y video (con un tamaño de $962 \mathrm{MB}$ ); "Van Gogh: The Starry Night" (\$4.99), publicado en 2012, tiene 48 páginas y un tamaño de 65.3 MB.

\section{The New Museum: el sueño de cualquier investigador}

Quizás no es de los más conocidos, pero eso no quiere decir que The New Museum no sea importante. Es una de las pocas instituciones que pone a disposición del público, de forma gratuita y digital, casi toda su fuente de materiales sobre publicaciones, exhibiciones y programas públicos. 
La colección está accesible en su portal web www.newmuseum.org, recoge 38 años de historia - desde la fundación del museo-y se compone de aproximadamente 7.500 registros escritos y visuales, así como de una base de datos navegable sobre más de 4.000 artistas, curadores y organizaciones asociadas con la programación del museo.

Desde luego la entidad tiene reglas sobre el uso de los materiales y sus derechos de autor; todo lo nuevo es procesado, digitalizado y añadido al archivo digital para estar disponibles.

En el buscador cronológico podemos ir hasta la primera exhibición, realizada entre junio y julio de 1977. La curadora, Marcia Tucker, presentó el trabajo de varios artistas en ese entonces apenas conocidos; si se avanza en el tiempo encontraremos nombres tan importantes como Andy Warhol, cuya obra "Jackie", en honor a la ex primera dama Jackie Kennedy, formó parte en 1991 de una exposición denominada "La vida interrumpida", que abordó el tema de la muerte, y Jean Michel Basquiat con las obras que formaron parte de "El Show de la Década: Marcos de la identidad en los años 1980".

\section{Una aventura científica}

Explorer es la app del Museo de Historia Natural de Nueva York. Es sumamente fácil de navegar, y ayuda al visitante - tanto presencial como a distancia- a no perderse detalles de nuestro fascinante universo.

Actualmente nos permite acceder a las exposiciones de "La ballena azul", "El tiranosaurio Rex", "la cultura rapa nui", 'Estrella de India", "Lucy" (uno de nuestros primeros ancestros el Australopitecus afarensis), "Los barosaurus", "El meteorito de Cape York", "la sequoia gigante" (árboles originarios de California) y "La Gran Canoa", uno de los artefactos más populares del museo, la cual posee diseños de distintas culturas nativas del noreste.

También resume en unos cuantos clics las exhibiciones permanentes: Mamíferos, Dinosaurios y fósiles, Aves, Anfibios y reptiles, Invertebrados, Biodiversidad y conservación, La Tierra, El Espacio, El origen del ser humano, Peces y Culturas del mundo. Nos lleva además por los pabellones más destacados como el de los Mamíferos avanzados (caballos, mamuts, tigre dientes de sable, mastodontes y cetáceos), Mamíferos africanos, Culturas africanas, Mamíferos asiáticos, Culturas asiáticas, el Teatro del Big Bang, Aves del mundo, Biodiversidad, Camino Espacial, la Furia de la Naturaleza, entre otros.

Una vez dentro del museo, la app orienta a los visitantes a cómo llegar y qué objetos destacados se encuentran en las cercanías.

El sitio www.amnh.org es un gran compendio informativo científico y de entretenimiento, mediante este se puede comprar desde artefactos y juguetes 
curiosos en la tienda del museo hasta reservar un cupo en las expediciones mundiales al lado de reconocidos expertos.

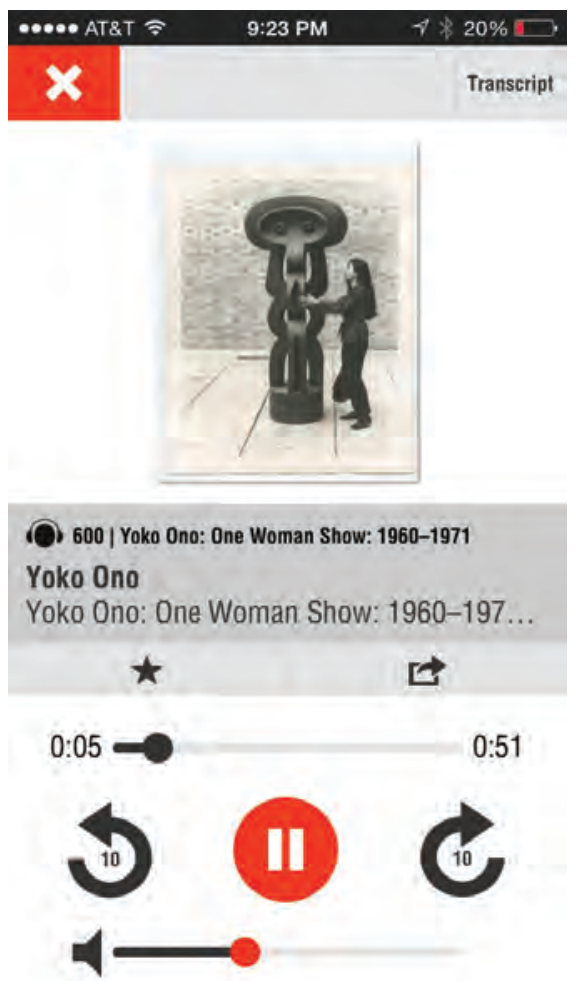

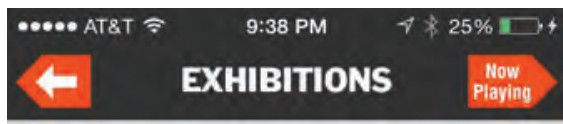

Yoko Ono: One Woman Show, 1960-1971 Through September 7
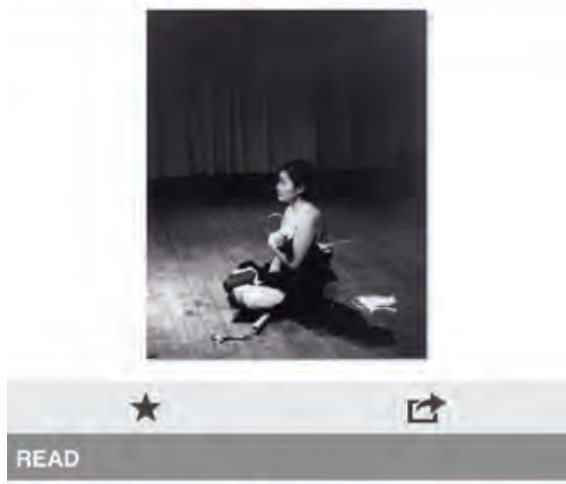

About this exhibition

The Museum of Modern Art presents its first exhibition dedicated exclusively to the work of Yoko Ono, taking as its point of departure the artist's unofficial MoMA debut in late... MORE

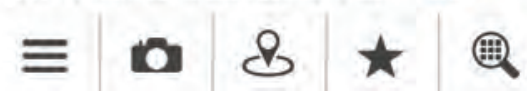




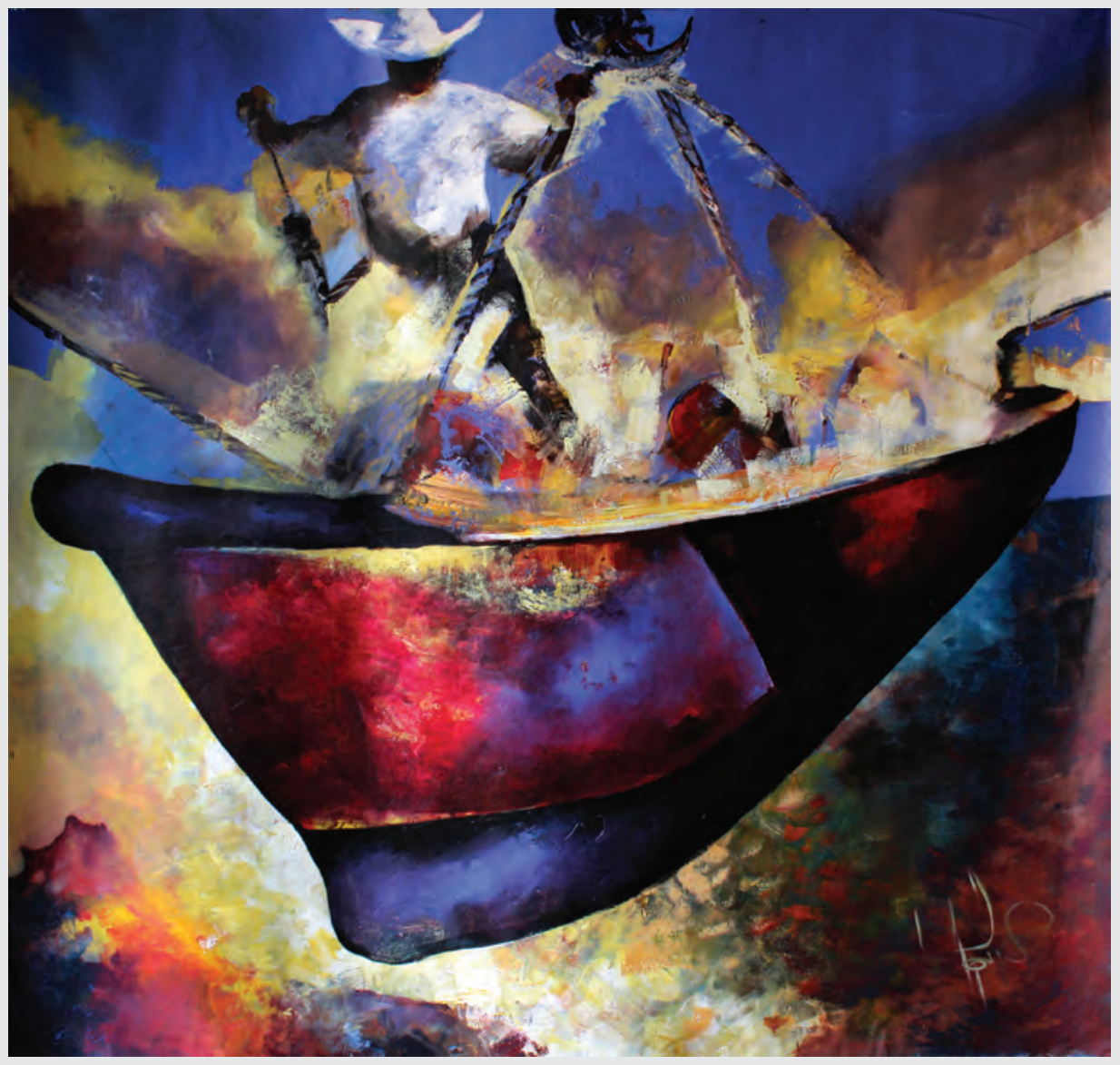

"Pescador de luz"

Medidas: 148 x $148 \mathrm{cms}$

Técnica: mixta

Año: 2009-2010 